\title{
Volumen 8
}

\section{Cultura i finances a l'Edat Moderna}

\author{
JoAN ANTONI GONZÁlez y Roc SALVADO POY, \\ (Centro Asociado de Tortosa, UNED)
}

El volum VIII de les Obres Completes del P. Batllori conté, juntament amb el VII, una sèrie d'escrits de procedència diversa que estan relacionats amb l'orde dels jesuittes als segles XVI, XVII i XVIII. Els editors els han agrupats en cinc grans blocs.

\section{L'ENSENYAMENT: D'IGNASI DE LOIOLA A LA RATIO STUDIORUM}

Per tal de dur a terme la difusio i defensa de les veritats catoliques, els membres de la Companyia de Jesús havien de tenir una preparacio adient $i$, per tant, calia un sistema educatiu que els la proporcionés. Aquest bloc està format per un conjunt de vuit articles referents als principis basics que sustentaven aquest sistema i als espais creats per a dur-lo a terme: les residencies i els col-legis.

Aix́, en el primer dels articles, Sant Ignasi $i$ la fundació dels primers col-legis, el P. Batllori ens explica com, a les Constitucions, Ignasi vol deixar establert el sistema educatiu que l'orde ha de desenvolupar. Per a la formació dels aspirants es pensa primer en tenir unes residències a prop de les universitats on aquells estudiaran, però prompte es creu convenient la fundacio de col-legis que siguin, a més, espais on els aspirants que no tenen preparació suficient per a les classes universitàries puguin adquirir-la. D'aquí es passarà a permetre l'assistència a les classes a qualsevol persona que vulgui assistir-hi amb la qual cosa es convertiran en centres d'ensenyament oberts a tota la societat.

A continuacio estudia els trets essencials dels col-legis segons el país on eren ubicats. A Els col-legis a Espanya, ens diu que el primer va ser el de Gandia, fundat per St. Francesc de Borja; en aquests col-legis només es feia l'ensenyament inferior i mitjà. Cap no obtingué el tútol d'universitat, ni tingué facultats de dret o medicina.

La cosa fou molt diferent a Italia, com veiem al tercer article, Els col-legis a Italia. Ja el primer col-legi, el de Messina, dirigit per Jeroni Nadal, obtingué la 
categoria d'Universitat de mans del Papa Pau III. En ell els jesuittes emprengueren la primera experiència d'ensenyament renaixentista en tant que humanístic, però en moral i religió era cristocèntric. S'intentà una síntesi d'experiències italianes (lliçons magistrals) i europees (sobretot dels col-legis parauniversitaris de París) que s'aplicaria a la resta de centres.

Al quart dels articles, Llengua $i$ nacionalisme en els col-legis francoitalians, el P. Batllori destaca l'especial situacio dels col-legis establerts als territoris aleshores pertanyents als ducs de Savoia, on coexistien les llengles francesa i francoprovençal. Allí el desenvolupament fou diferent per les condicions socials de la zona. Així, al col-legi de Chamberry, la majoria del personal era de llengua francesa (savoians i francesos), però s'integraren en l'estat savoià i participaren en festes i actes oficials.

El fet que el sobirà de Savoia mantenia una certa unitat entre estats de cultura diversa contrasta amb el comportament dels monarques francesos, que tendiren a homogeneïtzar els seus territoris (Catalunya nord, baixa Navarra).

A continuaci6 el P. Batllori estudia la Ratio studiorum, el sistema pedagdgic que s'utilitzava als col-legis dels jesuites. Les primeres normes van ser establertes per St. Ignasi, però en anys posteriors algunes van ser modificades $i$ se'n van implantar de noves. Tracta el tema en tres articles: Elements pedagdgics, on veiem que dins la Ratio quedava tot establert: tipus de collegis, funcions dels membres (rector, prefecte, professors...), assignatures, llibres de text (quins autors s'havien de llegir i quins quedaven prohibits), practiques de treball i religioses, activitats extraescolars... Aixd porta a la llarga a un estancament (per exemple en l'estudi de les ciències físiques i medicina) $i$, encara que els avenços de la ciència van obligar a una modificací parcial de la Ratio portada a terme pel P. Joseph de Jouvancy el 1692, aquesta no fou suficient per evitar gran nombre de queixes, les quals tingueren forta influència en la supressió de la Companyia el 1773.

A l'article La formació de la consciencia catolica moderna tracta de la influència que la Companyia, per mitjà de l'educació que es donava als seus col-legis, tingué en la societat civil de l'època. Com als col-legis de jesuittes podia estudiar la joventut dels llocs on eren establerts (en molts casos eren els unics centres escolars), aquest fet es va aprofitar per a convertir-los no tan sols en centres d'ensenyament, sinó tambe d'espiritualitat, on se celebraven actes litúrgics i sacramentals. Cal afegir la pràctica d'obres de misericordia -com la visita als hospitals - , el teatre religiós i les missions. Tambe va ser important la practica dels exercicis espirituals, però nomes es van aplicar els penitencials.

El tercer dels articles sobre la Ratio, Entorn de la nova edició crítica de 1986, es un comentari a l'edició del volum V dels Monumenta paedagogica Societatis lesu, editat per Ladislaus Lukáks S.I., que comprèn els textos jurídicopedagogics referents a la Ratio de 1586, corresponents al generalat de Claudio Acquaviva. El resultat de l'estudi, segons el P. Batllori, és d'una gran ponderació, lluny d'una apologia a ultrança de la pedagogia jesútica.

Aixi, presenta les quiestions que, en matèria d'ensenyament, preocupaven en aquell moment els jesuites, com la llibertat d'opinions i la selecció de les 
proposicions de la Summa de Sant Tomàs que no havien de ser imposades i la de les obligatơries. Queda pales com, enfront dels uniformistes, que pretenien que fos inamovible la norma del fundador que tots pensessin i parlessin igual, hi podia haver una certa llibertat en el cas dels professors de teologia, basada en una solidesa doctrinal i un mínim de llibertat, i encara més en els de filosofia, per als quals no es dóna cap llista d'opinions que haguessin d'ensenyar o descartar.

Tot aixo fa que aquesta Ratio superi en valor humà $i$ humanfstic a les posteriors de 1591 i 1599, ja que reflecteix la innovació pedagdgica i crítica imposada pel Renaixement davant el caricter més ordenancista i immobilista de les seglients.

A l'article que tanca la primera part del volum, Les obres de Joan-Lluis Vives en els col-legis jesultics europeus del segle XVI, el P. Batllori vol explicar (no justificar) les raons per les quals els llibres de Vives (i també els d'Erasme) foren prohibits a les escoles jesuítiques, especialment a la de Roma, mentre que la prohibicio no fou tan taxativa per a les altres, sobretot quant més allunyades estaven d'aquella ciutat.

Dues són les raons -ens diu - que tenia St. Ignasi: el fet d'estar sotmés a diversos processos inquisitorials, que l'obligava a moure's dins la més estricta ortoddxia, i la voluntat de servei de l'orde al Papa. Aixd fa que Ignasi tingui una certa prevencio cap a les obres dels cristians no totalment ortodoxes, doncs creu que, encara que algunes siguin bones, la seva lectura farà que se'n vulgui llegir la resta, mentre que els autors pagans, expurgats, no presentaran cap problema.

A la mort del fundador els segulents prepdsits van oscil-lant: mentre Lainez i Borja, anul-len les prohibicions de les obres didactiques de Vives, Mercurià les torna a prohibir totalment i el cinque, Acquaviva, no ho fa taxativament.

Alguns aspectes de la pedagogia de Vives entraren en la dels jesuittes: la importancia dels jocs dels infants per a l'educació, l'exercitació de la memòria, l'ensenyament del llatf i del grec i l'equilibri de fons i de forma en la composició literaria en són un exemple.

\section{LES FINANCES D'UNIVERSITATS I COL·LEGIS}

Despres d'haver vist l'ensenyament i els principals col-legis, la segona part de l'obra correspon a la investigació de la financiació d'aquestos. En cada un dels estudis ofereix nombroses dades documentals i quantitats exactes dels diferents ingresos $\mathrm{i}$ despeses que permeteren el funcionament dels col-legis, extretes de documents de l'època. Aquesta part comprèn cinc estudis.

Al primer, Tipologia fundacional, el P. Batllori explica com, una vegada acceptat que s'havien de crear residencies i col-legis dins l'orde, calia trobar mitjans de financiació dels mateixos que no estiguessin en contradicció amb la pobresa exigida als membres, i tot seguit fa un estudi de les principals fonts que permeteren fundar i mantenir els col-legis, suportant els problemes econdmics generals de l'epoca. 
Per portar-lo a efecte, tria un col-legi característic de cadascuna de les possibles fonts de financiació i aporta nombroses dades tant dels ingressos com de les despeses, relacionant-les amb el nombre de professors $i$ alumnes, cosa que li permet de fer veure l'abundància o modèstia amb què es vivia a cadascun d'ells. Les fonts poden ser:

I. Fundació pontificia. El primer dels col-legis estudiats és el de Roma. Al principi va comptar amb donacions de Francesc de Borja i d'altres persones a títol individual, perd prompte van ser insuficients i va ser Gregori XIII qui va proporcionar unes elevades fonts d'ingressos, en rendes i en edificis, de manera que el col-legi adoptarà el nom d'Universitat Gregoriana. Així $\mathrm{j}$ tot, amb el temps tampoc no foren suficients $i$, com la majoria de col-legis, hi hagué un dèficit que es compensava amb donacions.

II. Fundacio municipal. El col-legi de Messina va ser financiat pel municipi. Aquest va demanar la creació d'un centre que fos universitat, i així va ser aprovat per Pau III. Durant la seva existència va haver-hi conflictes entre ambdues parts, excepte el perfode 1590-96. En aquest any el col-legi se separà de la universitat $i$ les rendes decaigueren, trobant-se en grans dificultats economiques.

III. Fundació privada. La fundació del col-legi de Sàsser es degué a la voluntat del sassares Aleix Fontana, jurista de la Cancelleria de Carles V per a la Corona d'Aragó, qui deixà en el seu testament unes rendes per a la seva financiacio. Abans s'obrí el col-legi amb altres donacions que resultaren insuficients, però les coses milloraren en assumir l'herència.

Més endavant hi hagué la donació d'un altre sassarès, Gaspar Vico, per a la creació d'una universitat. Aquesta s'aconseguí després d'un conflicte amb la de Căller, però les rendes eren insuficients i el Col-legi-Universitat de Sàsser portà una vida modesta fins que el rei de Sardenya Carles Manuel III de Savoia li donà estabilitat.

IV. Fundació episcopal. El bisbe de Clarmont, Guillaume du Prat, acordà amb els jesuïtes la fundació de tres col-legis en ciutats que no eren seus episcopals - París, Billom i Mauriac - i a tal efecte els deixà unes rendes que foren ampliades amb nombroses donacions d'altres fonts. Tot $\mathrm{i}$ així, el col-legi de París mantingué el nom de Clarmont fins que el 1683, per les rendes concedides per Lluís XIV, passà a dir-se College Louis-le-Grand.

V. Fundacio imperial. El Col-legi de Viena fou creacio de l'Emperador Ferran I; les rendes que oferi foren ampliades per Maximilia II amb la cessio de béns d'altres ordes religiosos. El col-legi no passà problemes econòmics i permetè la recuperació de l'Església catòlica en aquesta part d'Europa.

VI. Fundació imperial. L'últim dels col-legis tractats és el de Madrid, la creació del qual es degué a Leonor Mascarenhas el 1561, ampliat després per Joana d'Âustria i consolidat gràcies a una fundació de la vídua de Maximilià II, Maria d'Âustria, per la qual obtindrà el nom de Col-legi Imperial.

La resta dels estudis d'aquesta part, es dediquen a aquells centres que per una $\mathrm{O}$ altra rá van tenir una certa importància dins el conjunt dels de l'orde. El 
primer d'ells, dedicat al de Sàsser, La Universitat de Sasser $i$ els Col-legis de Sardenya, és l'estudi més ampli recollit en aquest volum. En un centenar de pàgines, el P. Batllori ens explica amb gran detall la historia de la fundació del collegi, ampliat després a Universitat, i la seva financiació inicial (ja tractada al punt III de l'estudi anterior).

A continuació parla de la figura del fundador, Aleix Fontana, cavaller sassarès, humanista cristià i seguidor d'Erasme. Segueix una completa descripció de l'economia del col-legi durant el segle XVI, presentant els comptes dels anys 1567 i 1579. Després esmenta els altres col-legis de l'illa, Caller i l'Alguer, i els noviciats de Busaqui i Esglésies, les vicisituds de les seves fundacions, les rendes i la procedència d'aquestes. Per últim fa unes reflexions relacionant l'economia dels col-legis amb la de l'illa de Sardenya i com aquesta condicionava la d'aquells.

L'estudi es complementa amb un apendix on figuren les copies dels documents que corroboren el tractat: testaments que feren possible la creacio del col-legi, cartes del preposit dels jesuites de Sardenya i dels consellers de Caller al General de l'orde i una altra del Rector de Sàsser al preposit provincial. Aquesta part es conclou amb l'informe sobre l'estat de la Universitat de Sàsser amb data d'1de juny de 1660 .

En el segon estudi, El Col-legi de Sant Pau a Ratisbona, ens explica que en aquesta ciutat imperial, on coexistien catolics i protestants, fou creat un col-legi gràcies a la insistència de Guillem V, duc de Baviera, qui hagué de vèncer les reticències del capítol catedralici i obtingue l'edifici del monestir de St. Pau per a la instal-lació.

El col-legi tingue, al principi, un nombre fluctuant de sacerdots i alumnes i les rendes foren insuficients fins que obtingué els mateixos privilegis que la resta de col-legis bavaresos $i$ altres ingressos no fixos; l'etapa millor va ser cap el 1632 , amb uns 50 estadants.

Posteriorment, la conquesta de la ciutat pel duc de Weimar provocà la expulsió dels jesuîtes i la devastació de les propietats rurals. Encara que mig any després pogueren tornar, el col-legi no tornarà a ser complet fins començar el segle XVIII.

En el seglient estudi, Del Col-legi a la Universitat de Malta: Una fundació del bisbe Gargall, el P. Batllori ens diu que el papa Climent VIII cred el Col-legi de jesuittes a Malta el 1592, essent bisbe de la diocesi el català Tomàs Gargall, qui inflú decididament en la creació pensant a instituir un seminari tridentr. Així restà sota la dependencia directa del bisbe i havia de tenir una activitat preferentment pastoral.

Però en tenir els cursos complets de filosofia i teologia, era jurídicament un col-legi universitari i posteriorment, en crear-se el seminari diocesd, es convertf en universitat, encara que prengue el títol d' «Academia». El perquè el justifica el P. Batllori per una questio de competències: el Gran Mestre de l'illa tenia vincles feudals amb el Rei de Sićlia, el qual seria en última instància qui podria donar l'autorització. L'Acadèmia, pero, després de l'expulsió dels jesuittes, es convertí en Universitat pontifícia. 
Com en altres centres de la Companyia, les rendes provenien de béns de la regio, cosa que feia que fossin inferiors a les que es podien obtenir si les haguessin invertit en altres llocs de més potencial econòmic.

L'article té un apèndix on s'ofereixen fins a 30 documents de caire economic referents al Col-legi.

L'últim dels estudis d'aquesta part, L'Academia Carolina d'Osnabrïck 1625-1773, es dedica a aquest centre situat en una ciutat episcopal on també convivien catolics i protestants. Fou creat per l'acció conjunta del bisbe von Hohenzollern i el capítol catedralici, de majoria catolica. La dotacio econòmica era elevada, amb la donacio de la capella de St. Pau i casa annexa, les rendes de l'Escola Carolina i els béns del convent abandonat dels agustinians, a més d'altres donacions, completades amb la fundacio academica. Tot va ser confirmat per Urbà VIII i l'emperador Ferran II.

Encara que fou una verdadera universitat, no prengué mai aquest nom per evitar conflictes amb les veïnes i no serà anomenat acadèmia fins el 1632. L'any segllent, el bisbe $i$ els jesuittes van haver de sortir a causa de l'avanç dels protestants i no fou fins el 1650 que tornà el bisbe i amb ell una "missio»" jesuftica que and creixent, tot i la mort del bisbe el 1661, gràcies a l'amistat que els dispensaren el lutera bisbe-princep d'Osnabrick i la seva muller, Sophie.

El col-legi, però, no aconseguí estabilitat juŕdica $i$ les despeses de construcció de la nova seu en debilitaren l'economia, encara més quan augmentà el nombre de residents i d'escoles fins a tenir el curs de filosofia complet. No fou fins el 1714 quan hi hague un cert equilibri financer.

El treball inclou un quadre-resum de les dades econdmiques que resten del col-legi des de l'any 1661 fins el 1770 .

\section{ENTORN A LA CULTURA DEL BARROC}

La tercera de les parts comprèn uns articles de procedència força variada, la temàtica dels quals sol ser la relació entre l'orde dels jesuîtes i el perfode cultural conegut com a Barroc. Aquesta relació és palesa sobretot al primer dels articles, Jesuitisme $i$ Barroc, on s'estudia la relació entre ambdós tant en el camp de l'arquitectura com en el de la literatura.

Referent a l'arquitectura el P. Batllori comenta que hi hagué estudiosos, com Burckhardt o Croce, que identificaven el Barroc amb un art «jesuític»; l'ultim autor arribà a dir que el Barroc o art jesuftic representava la davallada de l'art cristià.

El nostre crític no hi és d'acord; cita alguns autors, com Mâle o D'Ors, que discrepen dels anteriors i altres, com Friedrich, que veuen una unitat en l'art de tota Europa al segle XVII. Batllori creu que cal distingir dos problemes: a) els origens de la predilecció dels jesuittes per les esglésies d'una nau, com les del Gesú i St. Ignasi de Roma, i b) la imposició d'aquestos tipus d'església en la resta de construccions arreu del món. 
Respecte al primer, cita a Braun, per a qui fou F. de Borja qui imposà en el temple del Gesú la seva predilecció pel temple d'una nau, com el de Gandia, més apte per a la predicació i més pobre d'ornamentació.

El segon és més problemàtic: sí que hi hagué un «modo nostro» arquitectònic que s'aplicà a totes les construccions noves, perd̀ aquest es referia a la funcionalitat de les construccions per a la predicació $i$ la confesió, en els temples, i a l'ensenyament, en els col-legis, més que a un model únic.

Estudis posteriors, com els de Vallery-Radot i Bossel, donen noves llums que permeten afirmar que a Itàlia hi ha tres períodes diferenciats: els edificis del segle XVI estan vinculats al Gesú, els del segle XVII, a l'església de St. Ignasi i els del XVIII són el resultat de l'evolució del Barroc siscentista.

En l'època del Manierisme es permeté que els temples, destinats al culte, fossin més sumptuosos que els col-legis, reflex de la pobresa de l'orde. Si totes les esglésies semblen temples barrocs és perque van ser ornamentades en èpoques posteriors. El cas de l'excès de pompa d'alguns col-legis és perquè eren universitats o en feien les funcions. És el clima triomfal de la Contrareforma siscentista el que afavoreix la identificació de l'estil jesuític amb l'art barroc.

Respecte al Barroc literari, Batllori creu que s'ha de distingir entre l'estil en obra escrita i l'ensenyament de les arts de retorica i poetica. En conjunt són, com l'arquitectura, un desenvolupament dels metodes i normes del Renaixement tardà o del Manierisme.

En realitat, les normes proposades per St. Ignasi o F. de Borja i les posteriors eren frens contra l'evolució del Barroc, però primer en els sermons solemnes i després en tots s'admeté la pompa i el llenguatge culte; també en el teatre i en la poetica. En definitiva, els jesuites no foren creadors, sino receptors i després difusors de l'art barroc.

En el segon dels articles, Espectacles barrocs a Monti-Sion, insisteix el P. Batllori en negar la identificació entre Barroc $i$ jesuiltisme. Ara es recolza en García Villoslada i el marquès de Lozoya qui, a més de negar el fet, explica que a llocs com Napols l'ornamentació pomposa es degué a la necessitat d'atraure els fidels per tal que no assistissin a les festes del Carnestoltes.

Recolzant el fet, Batllori presenta un fragment del text Historia del Collegio de Nuestra Señora de Monte Syón, en el qual es diu com, per atraure la gent a la celebració del Corpus de 1649, cada dia s'ornamentà l'església d'una manera diferent, sempre amb gran pompa i espectacle.

A continuacio s'inclouen uns articles referents a les persones de dos jesuîtes de l'època. El primer d'ells, el portuguès Antonio Vieira s'estudia en dos articles diferents, L'ambaixada a Barcelona i Roma el 1650 i Una visió apocalíptica del futur de Portugal. En el primer ens diu que Joan IV de Portugal tenia pensat abdicar en el seu fill Teodosi si aquest es casava amb la filla de Felip IV, amb la qual cosa es tornarien a unir els regnes peninsulars, però ara amb sobirà lus. Per forçar la situacio, el monarca portuguès envià Vieira a Roma per tal de promoure malestar a Nàpols, cosa que, creien, facilitaria l'apropament. 
Vieira féu escala a Barcelona on, a més de ser rebut pel col-lector pontifici, intentà de fer veure als catalans les similituds amb Portugal en casos com el nomenament de bisbes. Una vegada a Roma no obtingué els resultats previstos, ja que l'ambaixador espanyol se'n va adonar de les seves intencions, encara que de forma incompleta, i va provocar la seva sortida del país.

En el seglient article fa esment d'un aspecte d'aquest jesuitta que havia estat bandejat pels estudiosos: el messianisme d'algunes de les seves obres. Batllori el relaciona amb altres dos visionaris de l'Edat mitjana: Amau de Vilanova i Joan de Rocatalhada: tots dos profetitzen l'arribada de l'Anticrist i la fi del món en una data exacta, basant-se en interpretacions personals dels llibres de Daniel i St. Mateu.

Vieira no profetitza la fi del món, sino el triomf de Crist i l'arribada del cinqué imperi sota la guia de Portugal, cosa que cal relacionar amb la idea de Joan IV de casar el seu fill, primer amb una princesa francesa i després amb la filla de Felip IV; ambdós casos tingueren com a protagonista, encara que sense exit, el propi Vieira. La casa de Bragança, en la persona de l'infant Pere (futur Pere II de Portugal), havia de ser qui dirigiria l'imperi.

El segon dels jesuittes és l'italià Fulvio Fontana, de qui Batllori ens fa una petita biografia a l'article Les missions populars de Fulvio Fontana a la fi del Barroc. Aquest jesuitta fou professor als col-legis de Terni, de Parma i de Buseto i despres predicador. A partir de 1685-87 comença la seva tasca a les missions populars, primer amb un equip dirigit per Segneri i després com a principal predicador.

Les caracteristiques de la seva funció són un deix popular amb gran riquesa d'exemples $i$, sobretot, una «mise en scène» barroca acompanyada de processons espectaculars. Aixo feu que tingués uns resultats molt positius en la seva tasca. Les missions més importants el portaren a les didcesis de Como i Milà, així com als cantons catolics de Suïssa i, en 1710, al Tirol i a Viena.

L'últim estudi d'aquesta part, Una col-lecció d'edicions de teatre castella del Segle d'or a la Biblioteca provincial i universitdria de Barcelona, sense més relació amb els anteriors que l'època tractada, és el primer treball d'investigació que va portar a terme el P. Batllori a la Universitat de Barcelona amb el professor Jordi Rubió i Balaguer. Es tracta de la catalogació de 14 volums que contenen obres de teatre en castella que havien pertangut al convent de St. Francesc de Barcelona, almenys des de 1771 . En ser cremat el convent el 1835, una part de la biblioteca passà al monestir de Sant Joan de Jerusalem, també a Barcelona, on es formà la Biblioteca Provincial i Universitària.

La catalogació és una mostra del rigor i minuciositat amb què es treballava a la Universitat en l'època de Batllori. El resultat donà a conèixer a futurs investigadors l'existència d'unes obres fins aquell moment desconegudes. 


\section{ORIENTACIONS BIBLIOGRÀFIQUES}

Aquesta part recull un conjunt de diversos articles critics apareguts en diferents números de la revista Archiuum Historicum Societatis Iesu (AHSI), agrupats en dos grans epígrafs generals, el primer dit Entorn del jansenisme i de l'antijansenisme i el segon Barroc i Il'lustració.

Entorn del jansenisme $i$ de l'antijansenisme, originàriament en castella, conté diverses valoracions $i$ ressenyes al voltant d'obres que directament $o$ indirecta analitzen el tema tan debatut en el seu dia del jansenisme i antijansenisme.

Primerament es parla de l'obra dedicada al pare Lucien Ceyssens i els seus estudis al voltant del jansenisme i les aportacions d'aquest autor al coneixement de l'esmentada temàtica.

Després de tot un seguit d'apreciacions sobre el jansenisme a Belgica i la participació dels jesuittes en les campanyes antijansenistes, el P. Batllori conclou, amb inigualable prudència jesútica, però alhora amb la contundència pròpia del seu rigor com a investigador, que Ceyssens és poc sistemàtic a més de parcial i que certament realitza una aportació historiografica important al tema referit, però que tot $i$ aixf es troba lluny d'aconseguir realitzar una historia del jansenisme.

Dins d'aquest mateix apartat, Batllori afegeix unes Notes complementàries dedicades a la figura de Pascal en relacio a la seva postura favorable a les doctrines de Jansenius i la seva oposició enfront els jesuîtes:

I. Blaise Pascal. Oeuvres completes, I, text establert, presentat i anotat per Jean Mesnard.

El P. Batllori realitza una valorací general d'aquesta extensa obra relacionat-la amb moltes altres de tema pascalià; la considera més aviat una enciclopeddia pascaliana que una col-lecció d'obres completes i en critica la modernització ortografica dels escrits de Pascal i els documents que els acompanyen.

Com no pot ser d'altra forma, el P. Batllori fa esment de Les Provinciales, els atacs del filojansenista Pascal als jesuittes i la polèmica sobre la seva incerta retractació final. Conclou que les causes de la controvèrsia Pascaljesuîtes, més que en una polèmica teologica, caldria buscar-les en la incomprensió entre l'esperit matemàtic pascalia i l'esperit barroc de la Companyia.

II. Jean MESNARD, Pascal et les Roannez.

BLAISE PASCAL. Les provinciales ou les lettres écrites par Louis de Montalte a un provincial de ses amis et aux RR. PP. Jésuites, obra a cura de Louis Cognet.

Aquesta segona nota fa esment d'una altra obra de Jean Mesnard sobre Pascal. El P. Batllori valora molt positivament la tasca d'aquest estudiós 
sobre la figura del filosof, tot fent menció elogiosa de l'exactitud i minuciositat del seu treball, centrat ara en la incidencia de les relacions i del pensament pascalià amb la famflia noble dels Roannez; d'aquesta coneixença amical es desprèn el gran paper que van revestir per a la formació de la personalitat intel-lectual i religiosa de Pascal, alhora com aquest va influir decissivament en la trajectoria vital dels germans Roannez, Artus de Gouffier i la seva germana Charlotte. Aquesta darrera, segons afirmacions del P. Batllori amiga espiritual de l'autor frances, sota la influència de Pascal esdevingué sor Carlota de la Passió en el fogar jansenista de Port-Royal.

L'altra part de la nota està dedicada a valorar una edició de Les Provinciales i, especialment, la introducció de Louis Cognet a la mateixa, on destaca, en paraules del nostre crític, la precissio historica i doctrinal del seu autor a l'hora de resumir les polèmiques entre jesuittes $i$ jansenistes.

El segon epígraf, Barroc i Il lustracio, obre tot un seguit de referències crítiques i ressenyes al voltant bàsicament d'obres i personatges de l'època barroca i il-lustrada, sempre amb el rerafons de la historia dels jesuittes. Aquesta revisio, com la qualifica el P. Batllori, entorn de treballs, llavors recents, de les dues èpoques esmentades va ser originàriament escrita en italià per a la revista AHSI (1977).

El portic és l'aportació que significa l'obra de José Antonio Maravall, La cultura del Barroco: análisis de una estructura histórica, que jutja cabdal per a comprendre el Barroc hispànic. Batllori destaca molts aspectes de l'obra de Maravall, peró el que considera més rellevant és la idea d'aquest que la cultura del Barroc és una cultura dirigida i sotmesa a una doble orientacio, la dels grups dominants que volen perpetuar el seu domini i la dels moralistes (aqui Batllori esmenta el paper de Gracián i el seu Oráculo), preocupats de mostrar als homes de l'epoca l'art de navegar pels tumultuosos mars barrocs. Així mateix s'afirma que la barroca és una cultura de masses, tramesa de les elits al poble menut en un marc social cada volta més urbanitzat $i$ amb un sentit essencialment conservador, en el cas hispànic, per tal de reforçar i de justificar la monarquia dels Austries.

Valora, en segon lloc, molt positivament la traducció del castella al romanès de l'obra de Gracián Ordculo Manual, feta per Sorin Marculescu -Baltasar Gracián, Oraculul manual si arta prudentei. Criticonul - i publicada el 1975 en tres volums a Bucarest, traduccio que qualifica de sobria i precisa donada la dificultat de l'obra de l'escriptor aragones, que considera una de les més dificils de traduir.

Segueix una breu menció elogiosa a l'edició del cançoner atribuit al portugues Manuel Faria, aparegut en la segona meitat del segle XVII, feta pel professor de la Universitat de Michigan Edward Glaser l'any 1968.

La menció i consideració de Gracián per part del P. Batllori és pràcticament inevitable en totes aquestes notes crítiques i aixf, a l'hora de parlar del jesuita germanohispànic Eusebio Nieremberg, l'introdueix per la seva ocasional relació amb l'autor aragones travada en el jesuític Col-legi Imperial en el Madrid del Comte-Duc d'Olivares als inicis de la Guerra dels Segadors. 
D'aquest prolific escriptor en castella i llati en parla la monografia, considerada seriosa i preuable, del professor Hugues Didier, Vida y pensamiento de Juan E. Nieremberg. Batllori valora com a ben merescut l'homenatge retut per aquesta obra al poc conegut autor, únicament valorat fins ara pels historiadors de l'espiritualitat, del qual pondera la seva immensa i fastuosa erudició.

En la seguent nota el P. Batllori retorna al seu estimat Antonio Vieira (16081697) i fa esment de la seva activa vida pública, en concret del pas d'aquest personatge per Barcelona (1650), abans ja referit més ampliament, camí de Roma, amb la comanda secreta de facilitar una possible aliança matrimonial de la filla de Felip IV amb el fill del rei portuguès Joan IV, entronitzat per la secessió portuguesa, que haguès possibilitat un retrobament lusohispànic.

Tot aixo, interessant per a la historia política de l'epoca, ve a proposit del comentari a l'edicí́ crítica feta per José van den Besselaar de l'obra de l'autor portugues, Antonio Vieira, Historia do Futuro (Livro Anteprimeiro). Sobre aquest llibre es desplega l'interes del P. Batllori especialment sobre les fonts tant immediates com remotes de la concepció del mateix. La idea de Vieira sobre un cinquè imperi del món, amb capital a la Lisboa de Joan IV, recentment escapada del domini castellà, beu del darrer sebastianisme $i$, a travès d'ell, del context escatoldgic de la diàspora hebrea portuguesa establerta a Amsterdam, amb qui Vieira hauria mantingut contacte personal en raó de les seves embaixades als Paîsos Baixos el 1645 i el 1648.

Dins de l'estel dels Emblemes d'Andrea Alciato, es pot incloure l'obra del jesuîta torinès (ho fou només entre 1611 i 1635) Emanuele Tesauro (1592-1675) Idea della perfette imprese, manuscrit inèdit publicat per la professora Maria Luisa Doglio, que comenta breument el P. Batllori tot apuntant-ne una possible datació.

Tambe fa referència a aquest autor, juntament amb altres com Gracián, Vico i L. A. Muratori, l'obra de Giuseppe Conte, La metafora barocca: Saggio sulle poetiche del Seicento, que caracteritzà escuetament el P. Batllori.

Amb motiu del tercer centenari del naixement del tedleg, prevere i erudit italià Ludovico Antonio Muratori, sorgeixen tot un seguit d'obres al voltant d'aquest escriptor que ressenya el nostre critic, entre elles les actes del congrès (4 vol.) portat a terme a Modena el 1972 sota la direccio del professor Alberto Vecchi, centrades en la influència de Muratori en la Europa preil-lustrada; tambe fa esment de l'aparició d'una nova biografia sobre aquest personatge, obra de Matteo Schenetti.

A continuació de Muratori el nostre autor se centra en l'obra del gran historiador italia Franco Venturi, Settecento riformatore, II: La chiesa e la reppublica dentro $i$ loro limiti, el marc cronologic de la qual (1758-1774) comprèn des de l'any anterior a l'expulsió dels jesuittes de Portugal fins l'any posterior a la dissolucí́ papal de la Companyia de Jesús. Són, per aquesta temàtica, els tres capítols inicials de la referida obra els que més atreuen l'atenció del P. Batllori; en ells s'analitza el ressd a Italia de les persecucions contra els jesuittes a Portugal, el seu foragitament de França i posteriorment dels dominis hispdnics, alhora que tota l'ampla campanya, «internacional guerra pamfletistaw en boca de Batllori, que es desenvolupa entorn del cas dels jesultes. 
Aquest clima polèmic és el brou de cultiu de l'esclat del reformisme polític que s'escampa per la Itàlia dels anys 60 i 70 del segle XVIII -Gènova, Torí, Milà, Nàpols, Venècia - excepte el territori dels Estats Pontificis.

Instal-lat ja al segle XVIII, Batllori passa al món peninsular hispànic per referir-se a una figura cabdal del període preil-lustrat, el valencià Gregori Maians i Siscar, a proposit de l'obra de Vicent Peset, excel-lent en opinió del crític, Gregori Mayans $i$ la cultura de la ll.lustracio, en la qual es dóna notícia dels jesuîtes amics $i$ admiradors del savi valencià, tot i el seu antijansenisme, $i$ la influència que aquest valencià exercí en molts dels membres de la Companyia.

De València, sense abandonar el XVIII, Batllori salta a Mataró per ponderar la figura del mataroní Josep-Manuel Peramàs i Guarro, historiador jesuîta, analitzada genealdgicament per Pere Molas i Ribalta, Societat $i$ poder polític a Mataro 1718-1808. També ho fa el diplomàtic pontifici Jaume GonzálezAgapito en el nivell de les obres publicades pel referit jesuita a l'obra Bibliografia de Matarb. Els clergues del segle XVIII.

Al voltant de la percepció de les novetats cientifiques i la seva recepció als col-legis jesuítics hispànics, el P. Batllori destaca l'obra de Norberto Cuesta Dutari, El maestro Juan Justo Garcta, presbitero natural de Zafra 1752-1830, segundo catedrático de algebra de la Universidad de Salamanca desde 1774 y creador de su Colegio de Filosofia en 1792, tot remarcant que aquestes novetats no eren tan desconegudes en els establiments educatius de la Companyia ni els seus docents n'eren tan refractaris com habitualment s'ha vingut suposant.

Un altre jesuïta il·lustrat és el sevillà José de Silva, biografiat pel P. Pedro Herrera Puga, Una personalidad inédita de la Ilustración: el P. José de Silva (1740-1829), obra qualificada de massa apologètica i un xic precipitada, però al capdavall, útil.

Al voltant del reformisme del segle XVIII i una sèrie d'investigacions propiciades pel desvetllament de l'arxiu privat del comte Rodríguez de Campomanes són algunes de les darreres revisions portades a terme pel $\mathrm{P}$. Batllori en l'article que ressenyem.

La figura d'aquell polític, al qual es considera un dels veritables artffexs de l'expulsió dels jesuîtes, és objecte d'estudi per part de Laura Rodríguez Díaz, Reforma e Ilustración en la España del siglo XVIII: Pedro Rodriguez de Campomanes. Batllori, contra l'opinio de l'autora, descarta que Campomanes pugui ser considerat un precursor del liberalisme, encara que se li poden reconèixer alguns aspectes liberalitzants enfront del comerç i els privilegis de classe.

Un altre treball referit a Campomanes és el de Luis Gil, Campomanes, un helenista en el poder; en ell s'estudia la formació cultural del polític del segle XVIII, especialment a l'entorn de la llengua i cultura gregues i els esforços del ministre per promoure l'ensenyament del grec classic i modern despres de l'expulsió dels jesuîtes. El treball de Luis Gil és valorat com una aportació important de cara a la cultura hel-lenística d'aquell moment a Espanya.

Aquest conjunt d'estudis crítics finalitzen amb l'obra de Walter Höflecner, Das Fach Geschichte an der Universität Graz 1792-1848, que mereix el 
qualificatiu de recerca acurada, centrada en l'ensenyament de la història a la Universitat de Graz, unida al Col-legi dels jesuites entre 1729 -erroniament surt 1792 a la referència bibliogràfica de la nota a peu de pàgina - fins 1848 , període ben ample que s'allarga abans i després de la supressió de la Companyia. Malgrat alguna reiteracio, referida als personatges estudiats, Batllori lloa l'estudi per la seva abundant documentació arxivística i la riquesa bibliogràfica.

\section{NOTES CRITIQUES}

L'últim apartat d'aquest volum, sota el títol de Notes critiques, aplega una amplíssima miscel lània de notes crítiques, escrites en diferents idiomes, de molt diversa procedència $i$ agrupades en tres grans grups temàtics: Universitats $i$ col-legis, El Barroc i Colofo als volums VI-VIII (I995-96). Moltes d'aquestes notes es troben referides als jesuites o hi figuren referències als mateixos; d'entre totes destaquem, per les sempre agudes i subtils percepcions del jesuitta catala, la transcripció d'un transmissió radiofonica del dos de maig de 1948, logicament en castellà, sota el títol - al llibre - de Cervantes de Roma estant, i l'entusiame pel prevere i escriptor tortosí Francesc Vicenç Garcia, demostrat amb motiu de prologar l'obra d'Antoni Mundo i Fuertes, Francesc Vicenc Garcia, rector de Vallfogona.

En conjunt, els articles són una mostra de l'erudicí i del rigor documental amb què el P. Batllori construila els seus articles, així com la cortesia demostrada amb els autors ressenyats, dels quals sempre ressaltava algun aspecte positiu encara que no estigués d'acord amb les opinions exposades o amb les conclusions a les quals arribaven a les seves obres. 